\title{
Ascencio Franco, Gabriel (COORD.) (2013), TeORÍA y PRÁCTICA DE LA EDUCACIÓN intercultural en Chiapas. MÉxico: UnAM-IIA-PROIMMSE.
}

\author{
Flor Marina Bermúdez-Urbina
}

1 finales de noviembre de 2013, Angelina, una joven mixteca que estudiaba en una secundaria técnica ubicada en el barrio de Tepito, en la ciudad de México, recibió una golpiza en las instalaciones de la escuela a la que acudía. Las agresoras fueron dos jóvenes mestizas que subieron un video con la agresión a la red social Youtube e hicieron comentarios discriminatorios en Facebook, en los cuales se señalaban cuestiones como ésta: "Esto es lo que se merece una india bajada del cerro a tamborazos".

Además de los golpes insistentes de los que Angelina intentaba defenderse, durante dos años esta joven recibió insultos constantes, le fueron destruidos sus objetos personales y fue expuesta a ofensas mayores, como ser orinada en los baños de la escuela. En el análisis que Angelina, su madre y su primo hacen de lo ocurrido, concluyen que todo esto pasó "por ser indígena".

Este tipo de episodios de violencia racista que ocurre en las escuelas urbanas y rurales, grandes y pequeñas, indígenas y no indígenas, no es un fenómeno aislado ni poco común, sino que forma parte de las realidades escolares que viven los indígenas que han sido formados en los programas educativos interculturales y en los que carecen de este enfoque.

Lo que le ha pasado a Angelina, y quizás a miles de jóvenes indígenas que están en las escuelas, forma parte de una preocupación nacional que nos lleva a preguntarnos en dónde deben estar la teoría y la práctica de la educación intercultural.

El libro Teoría y práctica de la educación intercultural en Chiapas es un esfuerzo sobresaliente para situar la investigación educativa y antropológica, así como las experiencias pedagógicas, en contextos culturales específicos sobre lo que hoy en día se conoce como educación intercultural.

El término educación intercultural ha tenido un efecto hipnótico sobre los múltiples discursos que se tejen en torno a la educación para y de los pueblos indígenas. En un inicio, los núcleos de investigación que recurrieron a su uso cifraron muchas esperanzas en su potencial como categoría analítica de las realidades culturales existentes en los espacios educativos y en su capacidad como paradigma de transformación de prácticas escolares anquilosadas y racistas, que históricamente han existido en los planteles educativos.

Flor Marina Bermúdez Urbina, profesora-investigadora del Centro de Estudios Superiores de México y Centroamérica de la Universidad de Ciencias y Artes de Chiapas, México. Correo electrónico: fmarinabermudez@hotmail.com.

Recibida: 29 de septiembre de 2014. 
Al haberle otorgado virtudes que sobrepasaban las potencialidades de las categorías hasta ese momento existentes - educación bilingüe y educación bilingüe bicultural-, produjo un efecto dominó no sólo en su incorporación como enfoque o categoría teórica, sino también como elemento discursivo de las políticas indigenistas en educación.

Sin embargo, pese a los importantes esfuerzos en su conceptualización y desarrollo, a la vuelta de un par de décadas muchos de los que llegamos a utilizarla hemos caído en la cuenta del efecto distractor y anestésico que esta categoría ha tenido en la interpretación y producción de cierto tipo de conocimientos sobre las realidades escolares, su papel en la legitimación de ideologías, ahora llamadas "neoindigenistas", y su efecto en el desarrollo de propuestas educativas centradas en la esencialización cultural de los pueblos indígenas.

Llegó a ser un concepto tan legitimado por la academia que adjudicamos el apellido intercultural a muchas propuestas educativas emergentes; incluso llamamos educación intercultural a proyectos alternativos que no lo eran, y mucho menos pretendían serlo. Un ejemplo de ello es el de los dos tomos de educación innovadora publicados por la SEP en los años 2004 y 2006, titulados Experiencias innovadoras en educación intercultural, cuya compilación colocó el mote de intercultural a muchas propuestas educativas que no se asumían como tales. En la emergencia de una crítica hacia la interculturalidad, se ha concluido que su efecto más devastador ha sido la invisibilización de la desigualdad racial, económica y genérica que fragmenta a la sociedad mexicana.

Los catorce artículos que componen el libro Teoría y práctica de la educación intercultural en Chiapas nos muestran varios espacios, conceptualizaciones y tiempos desde donde se puede generar un acercamiento a la educación intercultural, indígena, autónoma, alternativa, dialógica o entrecultural. Refiero estos términos sin el propósito de caer en el error de pensar que todos significan lo mismo, sino más bien porque son los nombres que los autores utilizan para referirse a sus propuestas.
A manera de estado de la cuestión, este libro muestra la existencia de cuando menos cuatro perspectivas teóricas para entender la educación intercultural para los otros, los diferentes, los colaboradores, los indígenas.

En el primer texto, escrito por Javier López Sánchez, se describe un panorama de las políticas lingüísticas en México. En los artículos siguientes, escritos por Bruno Baronnet, Khatia Núñez, Cecilia Alba Villalobos y Fernando Nava, la educación para los pueblos indígenas es analizada desde los fundamentos de la teoría crítica, en los cuales se coloca en el centro la desigualdad y la discriminación. Algunos de los análisis atraviesan la interseccionalidad de la discriminación - por clase, etnia y género-, además de mostrar el papel de las instituciones y ciertos actores educativos en la incorporación de discursos legitimados por el poder. En este sentido, es desde los espacios autónomos desde donde se renuevan las prácticas escolares y comunitarias y se cuestiona la desigualdad. Para estos autores, la interculturalidad fomenta prácticas de racismo velado y se apuesta por una educación antirracista encaminada a la construcción de la autonomía.

En los textos de María Bertely, Francisco Arcos, Stefano Sartorello y otros coautores se realiza una propuesta de trabajo colaborativo que aporta elementos dialógicos y complementarios a los procesos de educación intercultural. En estos textos se plantea la existencia de una cultura indígena valiosa que necesita ser redimensionada a través de prácticas educativas que permitan la incorporación de las lenguas indígenas y los conocimientos culturales de los pueblos originarios en los programas y planes de estudio.

Se apuesta por la construcción de diálogos y negociaciones en la producción del conocimiento colectivo, que ocurren en diferentes planos y realidades a través del método llamado inductivo-intercultural. Estas propuestas consideran la educación intercultural como un vehículo legítimo para construir el respeto al otro y la tolerancia entre culturas. Su aporte principal se encuentra en una intención clara de hacer de la educación escolarizada una práctica cercana y construida desde los actores escolares -indígenas y caxlanes-. 
Enel textode Arcos titulado "Nuestro aprendizajecon nuestros hermanoscaxlanes", sedeja verotradimensiónde los proyectos educativos interculturales. Arcos muestra que, si bien la colaboración con los educadores de la Unión de Maestros de la Nueva Educación para México le ha aportado importantes aprendizajes, en su discurso también expone la dificultad de romper con las jerarquías académicas naturalizadas históricamente, cuando concluye que: "como mencioné, somos de baja escolaridad, morenos, feos, con el español indígena y mal vestidos... Nuestros hermanos no indígenas con su función nos abren el camino para hacer llegar nuestra voz a las instituciones. Además, como son estudiados, son los encargados de los documentos y requisitos que piden la comprobación de nuestros proyectos".

Revertir una autopercepción desvalorizada de parte de los educadores comunitarios y del desarrollo de su agencia política continúa siendo un desafío en la construcción de metodologías de trabajo que involucran a diferentes actores.

En los artículos de Horacio Gómez Lara, Antonio Saldívar y Fernando Limón, gran parte de su argumentación se centra en la pérdida de lo valioso de los pueblos indígenas, el "otro", el niño o joven indígena que ha dejado su cultura para migrar; y que, por ello, abandona la escuela. Se hace hincapié en las crisis juveniles, se exaltan los relatos de los mayores "como los poseedores del conocimiento ancestral" y se ejemplifica la separación que se teje entre una idealización cultural y una dinámica social en constante cambio. En estos artículos, se atribuye gran parte de los males de los pueblos indígenas a las políticas aculturadoras implementadas por el Estado y sus agentes - maestros-; esta separación entre agentes y estructura pareciera generar un abismo insalvable. En estos artículos, desaparece el espacio para construir un encuentro inter-entreculturas y procesos.

Finalmente se encuentran los artículos escritos por Sarah Corona Berkin, Rebeca Pérez Daniel y Julio Cuevas Romo. Se trata de tres artículos abocados al análisis de materiales educativos interculturales y a los procesos comunicativos y de autoría que de ellos emanan. Los autores han articulado una línea de investigación que coloca en el centro una postura anti-esencialista de la cultura indígena y mestiza, y apuestan por el reconocimiento de la diferencia en todos los planos de la producción de conocimiento. Estos textos cuestionan el papel del investigador en el proceso educativo y hacen hincapié en lo compleja que resulta la investigación colaborativa, con las jerarquías claramente delimitadas y estructuradas en las prácticas y discursos que actualmente existen.

Mención especial merece el texto del lingüista Otto Schumann, quien cierra el libro con una invitación a prestar atención al estudio de las lenguas indígenas y a la diversidad de prácticas religiosas y políticas en las que dichas lenguas se ven envueltas a partir de su uso. Su papel como actor en diferentes procesos del diseño e instrumentación de la política lingüística en México lleva a Schumann a plantear la urgente necesidad de recuperar el estudio de las lenguas y su vigencia.

Este libro nos permite ubicar geográfica e intelectualmente algunos de los espacios en los que se encuentra la investigación educativa sobre los pueblos indígenas. Los artículos muestran que se investiga sobre la educación de los pueblos originarios en las escuelas indígenas, en instituciones y centros de investigación en donde colaboran lingüistas y antropólogos, en las discusiones y prácticas de agentes educativos - maestros-, en los espacios comunitarios de las regiones indígenas y en los materiales educativos.

La lectura de este texto me induce a plantear que, si bien estos espacios son centrales, en la investigación y la práctica sobre la educación, que forma a los niños y jóvenes indígenas, se pueden explorar otros territorios y nuevos espacios. Es imperante que la investigación sobre los pueblos indígenas cruce las fronteras de la ruralidad y pueda llegar a escuelas como la de Angelina, en las zonas urbanas, y que aporte pistas para abordar desde los agentes -indígenas y no indígenas - y sus estructuras el racismo, la discriminación y la visión androcéntrica que prevalece en planes y programas de educación nacional, propuestas pedagógicas, materiales educativos y prácticas cotidianas de los actores escolares. 
La educación que los pueblos indígenas construyen debe expandir su mirada y ayudarnos a entender qué pasa con la infancia y la juventud migrante, con los indígenas rockeros, grafiteros, punketos, cholos y darketos que están en las calles de las ciudades y en las comunidades. Aquellos que no quieren ir a la escuela porque, según dicen: "Ya no les sirve para nada, ni para aprender a contar".

Estudiemos las lenguas indígenas desde sus hablantes, los niños y jóvenes indígenas trilingües que venden productos en las calles o que tienen negocios trasnacionales, hasta los jóvenes mestizos que en las ciudades se divierten mofándose de la limitada dicción en español de los mayahablantes.

Este libro nos coloca como imperativo atender, desde la investigación y la práctica educativas, la emergencia de una sociedad indígena y mestiza dinámica que resignifica de múltiples formas su lenguaje y su cultura, y que no permanece estática, sino que es tan dinámica que escapa a los ojos de la nuevas y viejas generaciones de investigadores sociales y educativos, quienes nos encontramos muchas veces un paso atrás del dinamismo galopante y transformador de la realidad indígena. 